\title{
PHOTOCATALYTIC OZONATION FOR THE DEGRADATION OF TETRADIFON PESTICIDE ON Mn/TiO 2 UNDER VISIBLE LIGHT
}

\section{MADDILA S. NDABANKULU V.O. JONNALAGADDA S.B.}

Received: $16 / 12 / 2015$

Accepted: 29/02/2016

Available online: 13/04/2016
School of Chemistry, University of KwaZulu-Natal Westville campus, Chiltern Hills, Durban-4000, South Africa

*to whom all correspondence should be addressed: e-mail: sureshmskt@gmail.com

\section{ABSTRACT}

The photocatalytic activity of $\mathrm{Mn}$ doped $\mathrm{TiO}_{2}$ for the ozonation of tetradifon pesticide in aqueous solution was studied. Various loadings of catalysts $\mathrm{Mn} / \mathrm{TiO}_{2}(1 \%, 2.5 \%$ and $5 \%)$ was prepared and characterized by standard analytical techniques. Photocatalyzed ozonation with $2.5 \% \mathrm{Mn} / \mathrm{TiO}_{2}$ yielded $100 \%$ degradation and mineralization of tetradifon in $2.0 \mathrm{~h}$ under basic $\mathrm{pH}$ conditions. The extent of degradation of tetradifon pesticide and its mineralization were confirmed by GC-MS. For $10 \mathrm{mg} \mathrm{l}^{-1}$ of tetradifon, $0.1 \mathrm{~g} \mathrm{l}^{-1}$ of catalyst was found to be the optimum for effective mineralisation. The reused experiment confirmed that $\mathrm{Mn} / \mathrm{TiO}_{2}$ kept a good photocatalytic activity and stability, and it was a promising heterogeneous catalyst. The catalyst is fully recoverable and reusable multiple times with no loss of activity.

Keywords: Tetradifon; Advanced Oxidation; Photocatalyst; $\mathrm{Mn} / \mathrm{TiO}_{2}$; Degradation

\section{Introduction}

A wide diversity of organic contaminants is introduced into the water system from different sources, such as industrial sewages, agricultural run-off, pharmaceutical and chemical spills (Marc et al., 2003). Their toxicity, stability to natural decomposition and persistence in the environment has been the cause of much concern to the societies and regulation authorities around the world (Aragay et al., 2012). During the past several years, pesticides (Tetradifon) have been one of the most commonly applied insecticides in agriculture, industrial and medicinal products (Rissato et al., 2007). Because of their high toxicity and long persistence in environment, chlorine contains sulfonated aromatic compounds, as well as byproducts of their production, have become major environmental problems (Field and Sierra-Alvarez, 2008). Consequently, they can be present together with their degradation products in natural water resources. Contamination of waters and soil can also occur from pesticide discharges from manufacturing plants, from storage sites and run-offs from vegetation and soil. However, the pesticide residues on agricultural products cause detrimental effects on human health such as carcinogenesis, neurotoxicity, irregular reproduction and cell development. Therefore, the control of organic pollutants in water is an important measure in environmental protection. Among many processes proposed and/or being developed for the destruction of the organic contaminants, biodegradation has received the greatest attention (Angelidaki et al., 2000). However, many organic pesticide chemicals, especially those that are toxic or refractory, are not amendable to microbial degradation (Maddila et al., 2015a). Recently considerable much attention has been developed on the use of photodegradation with ozone as a means to oxidize toxic organic pesticides (Maddila et al., 2015b). 
In recent years, heterogeneous photocatalysis with semiconductors is commonly considered as a beneficial method, not only for the degradation of pollutants in waste water and air (Chong et al., 2010). Photocatalysis is proven to be as an excellent method over than others due to the use of oxygen as an oxidant, for photooxidation of the organic compounds at its chemical stability, nontoxicity, low concentrations and at low temperatures, relatively low cost, and to achieve comprehensive degradation and mineralization (Kabra et al., 2004). Photocatalytic degradation involves the use of certain semiconductors as catalysts for the production of the highly reactive radicals under light irradiation (Chen et al., 2010). The proficiency of this system is based on the production of reactive species, such as hydroxyl radicals, holes, superoxide anions. However, use of titania is diminished by its wide bandgap (3.2 eV), which requires ultraviolet irradiation $(\lambda<387 \mathrm{~nm})$ for photocatalytic activation to inject electrons into the conduction band and leave holes in the valence band (Dahl et al., 2014). To progress the reaction of titania by enhancing the separation of electron-hole pairs, there are different strategies to reduce electron-hole recombination rates and increase the photocatalyst efficiency, including doping titania with transition metal (Chen et al., 2010; Dahl et al., 2014). The photocatalyst for the photo-oxidation of organic compounds has conventional much significance as it is plentiful, economical, powerful, eco-friendly, and pollutants can be degraded effectively and ultimately mineralized to $\mathrm{CO}_{2}, \mathrm{H}_{2} \mathrm{O}$ and inorganic anions under visible light irradiation.

Ozonation is one of the best methods that give better results in the degradation of organic species at low concentrations in water and wastewater (Maddila et al., 2014a; 2014b). However, it is commonly chosen to removal of the pollutants present in water effluents due to its higher oxidation potential. In addition, heterogeneous photocatalytic ozonation has received great attention due to its high oxidation potential that originates from the formation of hydroxyl radicals as well as a lack of secondary pollutants generation compared with the homogeneous catalytic process (Fathinia et al., 2015). In this process, the presence of the heterogeneous catalyst surfaces induces the decomposition of ozone, and subsequently generates the hydroxyl radicals. As significant functional materials in solid catalysts, manganese loaded titania have been commonly employed because of their stability and abundance in nature, as well as their higher catalytic efficiency during the photocatalytic ozonation process. Our group has proved that photocatalytic ozonation with $\mathrm{Mn}$ doped $\mathrm{TiO}_{2}$ improves the degradation and mineralization of pesticide.

\section{Materials and method}

\subsection{Photocatalytic Ozonalysis Experiment}

For photoozone generation, the light source was a 500-W xenon lamp (CHFXQ500 W) with a UV filter that can cut off UV light with wavelengths shorter than $420 \mathrm{~nm}$ and a fischer ozone 500 generator was used. Ozone enriched oxygen stream was passed through a sintered glass (porosity 2) into the $50 \mathrm{~cm}^{3}$ reactor at a flow rate of $10 \mathrm{~mL}$ per min. The reactor temperature was maintained at $19 \pm 1^{\circ} \mathrm{C}$ by circulating water through double walled jacket. For each run, $20 \mathrm{~mL} 10 \% \mathrm{w} / \mathrm{v}$ of tetradifon and fixed ozone concentration $(0.05 \mathrm{M})$ and flow rate of $10 \mathrm{~mL} / \mathrm{min}$. A magnetic stirrer was used to ensure continuous mixing. Ozone concentration in oxygen stream was determined using KI method (Maddila et al., 2014a; 2014b). Before and after each of the experiment the flow rate and photoozone content were monitored in duplicate runs.

\subsection{Catalyst preparation}

The photocatalysts were prepared by deposition-precipitation method by impregnating Mn over titania. $1.6 \mathrm{~g}$ of $\mathrm{TiO}_{2}$ was suspended in $60 \mathrm{~mL}$ of deionized water under vigorous stirring for $30 \mathrm{~min}$. Then, $1.8 \mathrm{ml}$

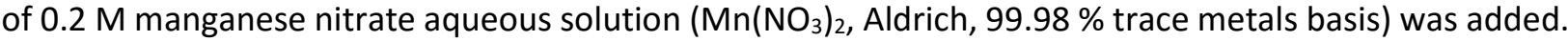
This solution was preserved unstirred for $1.0 \mathrm{~h}$. Then the manganese aqueous solution was added slowly into the $\mathrm{TiO}_{2}$ suspension under stirring. For the completion of addition, the $\mathrm{pH}$ was adjusted to 11 using $0.1 \mathrm{M} \mathrm{NaOH}$ solution. The suspension was vigorously stirred for another $2 \mathrm{~h}$. The precipitate was aged at $60-70^{\circ} \mathrm{C}$ for $2 \mathrm{~h}$ in the mother solution. Then the precipitate was filtered and washed with deionized water 
for three times. The samples were dried at $110-120^{\circ} \mathrm{C}$ for overnight and then calcined in the presence of air, at $450{ }^{\circ} \mathrm{C}$ for $4 \mathrm{~h}$ to obtain the $1.0 \%, 2.5 \%$, and $5.0 \% \mathrm{w} / \mathrm{w}$ of $\mathrm{Mn} / \mathrm{TiO}_{2}$ catalysts.

\subsection{Instrumentation}

All the catalyst characterization and product identification was achieved adopting the following techniques: PXRD, SEM-EDX, TEM, $\mathrm{N}_{2}$ sorption, ICP, PL, FTIR, GC-MS, ${ }^{1} \mathrm{H}$ NMR spectral analysis (Maddila et al., 2013a; 2013b; 2014c).

\section{Results and discussion}

\subsection{BET Surface and elemental analysis}

The $\mathrm{N}_{2}$ sorption study was carried out over bare $\mathrm{TiO}_{2}$ and $\mathrm{Mn}$ doped $\mathrm{TiO}_{2}$ catalysts (Figure. 1). $\mathrm{N}_{2}$ sorption resulted in typical type IV isotherm, with a $\mathrm{H} 2$ hysteresis loop. The BET surface areas of bare $\mathrm{TiO}_{2}$ and $\mathrm{Mn} / \mathrm{TiO}_{2}$ catalysts were found to be 38.45 and $79.82 \mathrm{~m}^{2} \mathrm{~g}^{-1}$, respectively. It is evident from these results that there was a significant change in the surface area from the $\mathrm{TiO}_{2}$ to $\mathrm{Mn}$ doped $\mathrm{TiO}_{2}$ catalyst. Table 1 summarizes the obtained BET surface area, pore diameter and pore volume.

Table 1: BET surface area, elemental analysis and band-gap of Mn loaded supports

\begin{tabular}{|c|c|c|c|c|c|}
\hline Catalyst & $\begin{array}{c}\text { Mn Wt\% } \\
\text { (From ICP) }\end{array}$ & $\begin{array}{l}\text { Surface Area } \\
\qquad\left(\mathrm{m}^{2} \mathrm{~g}^{-1}\right)\end{array}$ & $\begin{array}{l}\text { Pore volume } \\
\qquad\left(\mathrm{cm}^{3} \mathrm{~g}^{-1}\right)\end{array}$ & $\begin{array}{c}\text { Mn wt \% } \\
\text { (From EDX) }\end{array}$ & $\begin{array}{l}\text { Band-gap } \\
\text { Energy (eV) }\end{array}$ \\
\hline Bare $\mathrm{TiO}_{2}$ & & 38.45 & 0.24 & - & 3.20 \\
\hline $1.0 \% \mathrm{Mn}-\mathrm{TiO}_{2}$ & 0.98 & 51.66 & 0.16 & $\overline{0.98}$ & 3.10 \\
\hline $2.5 \% \mathrm{Mn}-\mathrm{TiO}_{2}$ & 2.46 & 64.48 & 0.14 & 2.48 & 2.84 \\
\hline $5.0 \% \mathrm{Mn}-\mathrm{TiO}_{2}$ & 4.98 & 79.82 & 0.10 & 4.97 & 2.76 \\
\hline
\end{tabular}

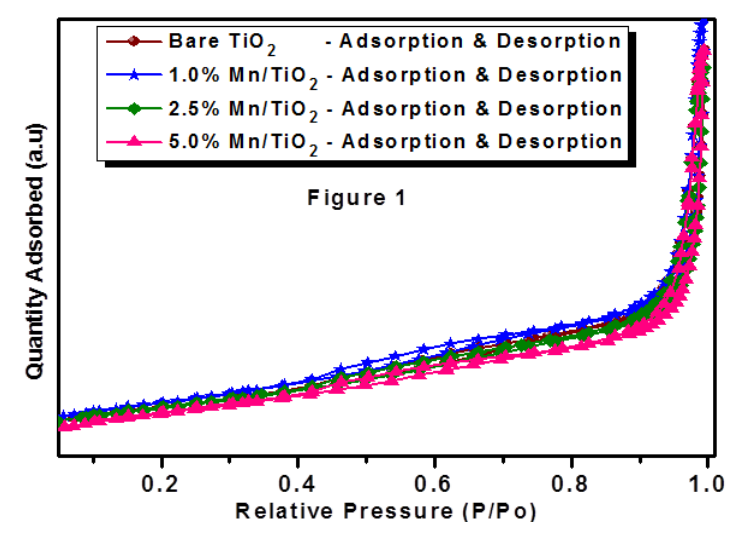

Figure 1. $\mathrm{N}_{2}$ sorption of $0 \%, 1 \%, 2,5 \%$ and $5 \% \mathrm{Mn} / \mathrm{TiO}_{2}$ catalysts

\subsection{SEM and TEM}

The morphology of bare and $\mathrm{Mn}$ doped titania (1\%, 2.5\% \& 5.0\%) catalysts were examined by scanning electron microscopy; the images obtained are presented in Supporting Information Figure. 2a-d respectively. The SEM images of bare titania and $\mathrm{Mn}$ doped titania at various amplifications display the partial crystalline nature. The surface morphology of titania appears to be changed after Mn loading. The EDX analysis evidently specifies the presence of $\mathrm{Mn}$ species on the surface of titania. The TEM images of the undoped and doped titania calcined catalysts and used are shown in Figure.3a-d. In these catalysts, the concentration of $\mathrm{Mn}$ increases average particle size decreases and the agglomeration between the particles also reduces. 

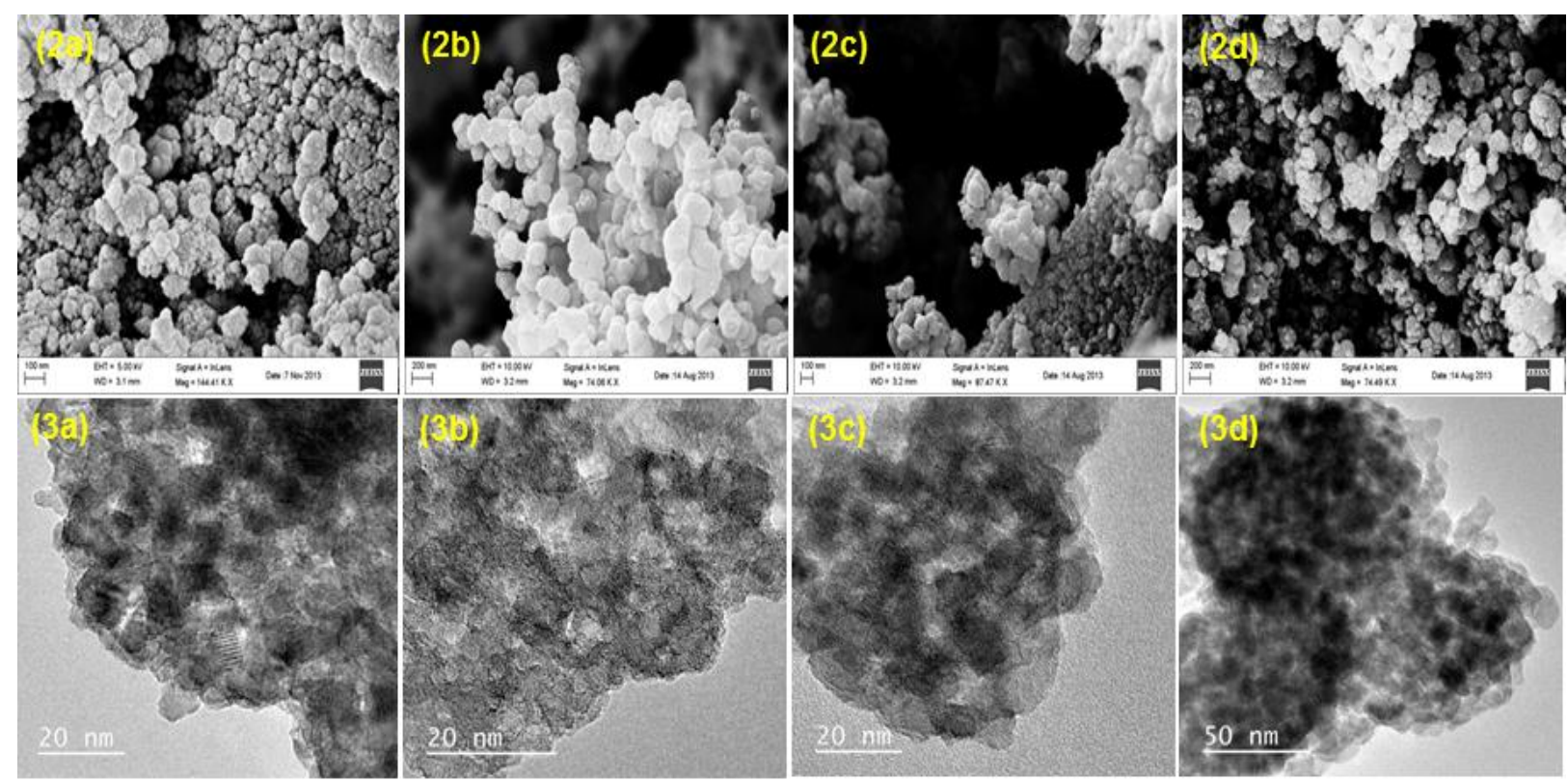

Figure 2 and 3 a-d. SEM and TEM images of (a) $\mathrm{Bare}_{\mathrm{TiO}}$, (b) $1 \% \mathrm{Mn} / \mathrm{TiO}_{2}$, (c) $2.5 \% \mathrm{Mn} / \mathrm{TiO}_{2}$ and(d) $5 \% \mathrm{Mn} / \mathrm{TiO}_{2}$

\subsection{XRD analysis}

Figure 4 shows the XRD diffraction patterns of bare titania and Mn doped titania (1\%, 2.5\% and 5\%) powder samples calcined at $450^{\circ} \mathrm{C}$. The diffractograms indicates peaks which corresponds to $2 \theta$ values of $25.3^{\circ}$ for $\left(\begin{array}{lll}1 & 0 & 1\end{array}\right), 37.8^{\circ}$ for $\left(\begin{array}{lll}0 & 0 & 4\end{array}\right)$ and $47.9^{\circ}\left(\begin{array}{lll}2 & 0 & 0\end{array}\right)$ (JCPDS file no. 21-1272) and are typical for anatase phase.

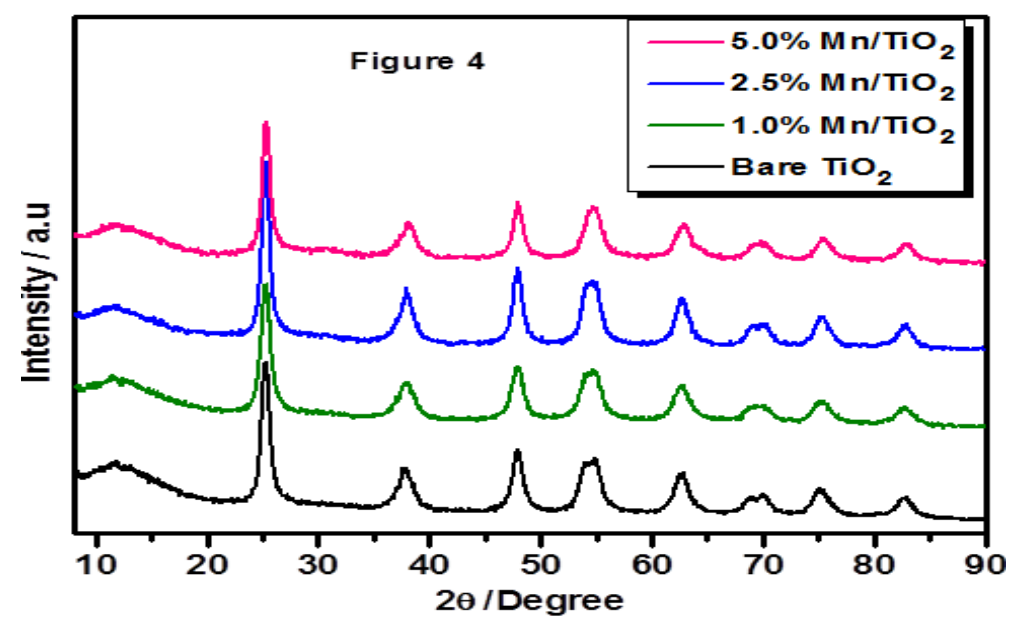

Figure 4. XRD images of bare and $\mathrm{Mn}$ doped $\mathrm{TiO}_{2}$

\subsection{UV-DRS}

UV-diffuse reflectance spectra of titania and various (\% $\mathrm{w} / \mathrm{w}$ ) Mn loaded titania catalysts are acquired in Figure $5 . \mathrm{TiO}_{2}$ has a strong absorption band at approximately $384 \mathrm{~nm}$ corresponding to band-gap energy of $3.2 \mathrm{eV}$ calculated from the formula $\mathrm{k}=1239.8 / \mathrm{Ebg}$ (Table 1S). On doping with $\mathrm{Mn}$, a red-shift was observed which could foster the photocatalytic activities of the catalyst under visible light. 


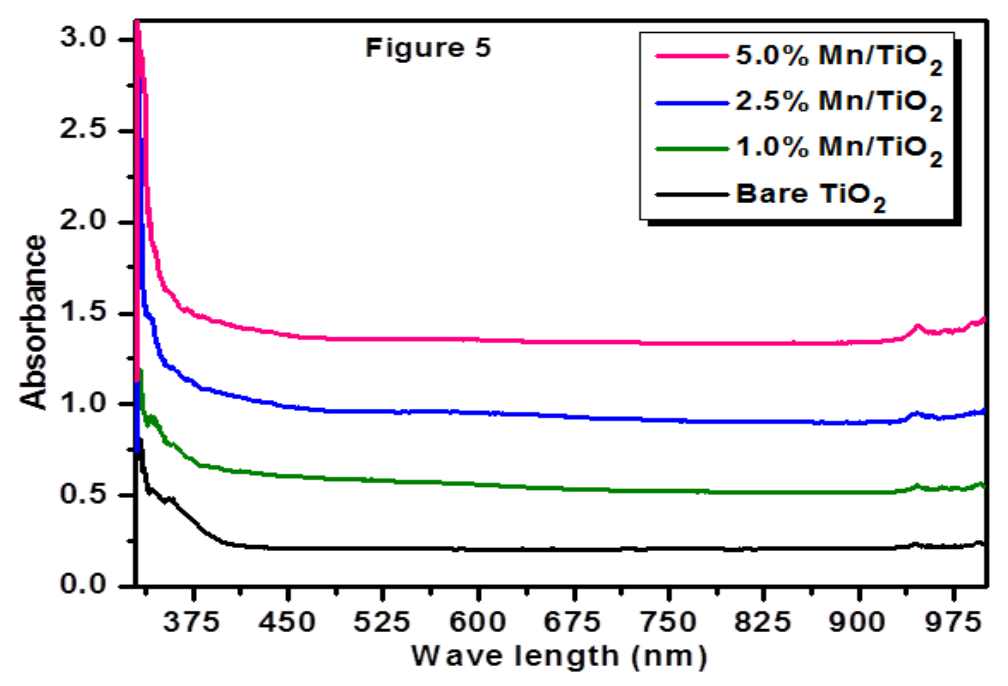

Figure 5. UV-DRS images of $\mathrm{Bare}_{\mathrm{TiO}_{2}}$ and $\mathrm{Mn}$ doped $\mathrm{TiO}_{2}$ catalysts

\subsection{Photoluminescence Spectra}

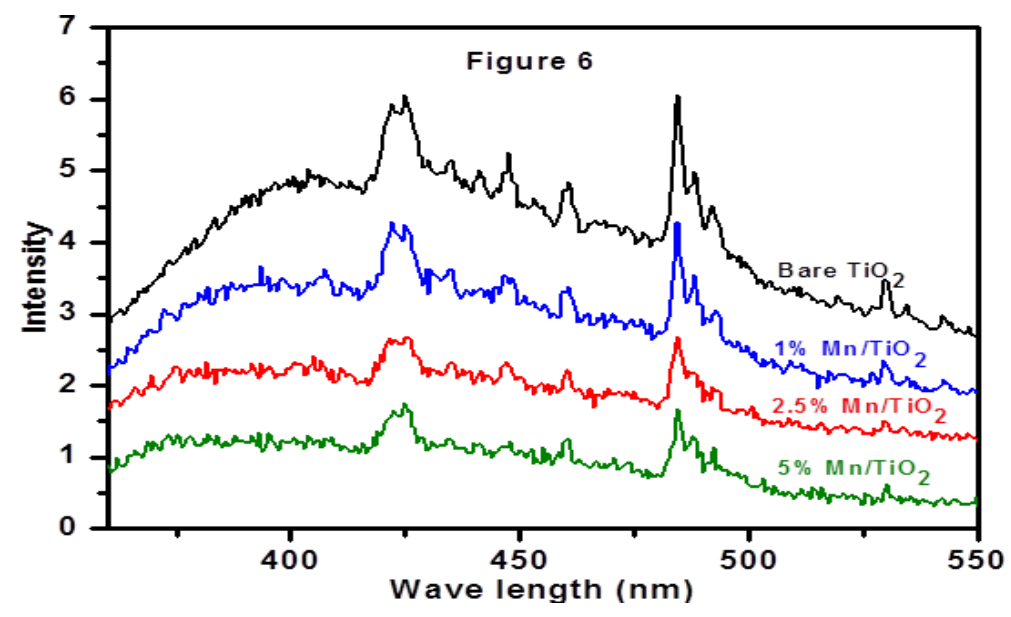

Figure 6. $\mathrm{PL}$ spectra of $\mathrm{Bare}^{\mathrm{TiO}} 2$ and $\mathrm{Mn}$ doped $\mathrm{TiO}_{2}$ catalysts

Figure 6 shows the PL spectra of samples in the range of 350-500 nm with the excitation wavelength of $360 \mathrm{~nm}$. The PL spectra might be closely related to the recombination of photo-induced electrons and holes, and free and self-trapped excitons, which possibly generate from surface defects in the $\mathrm{TiO}_{2}$ crystals, such as lattice distortions and surface oxygen deficiencies (Venier et al., 2014). The spectra show that the intensity of the $\mathrm{Mn}$ doped titania was decreased as compared to the bare titania, which indicates the reduction of the recombination centers for the electrons and holes in the samples. This describes that the $\mathrm{Mn}$ doped titania may have low electron-holes recombination rate under light irradiation and may show better photocatalytic activity than bare $\mathrm{TiO}_{2}$.

\subsection{Effect of $\mathrm{pH}$}

The influence of $\mathrm{pH}$ on the effectiveness of tetradifon degradation by ozonation is shown in Figure 7 . The degradation experiments were carried out at $\mathrm{pH}$ values of 3,7 and 11 . The degradation rate increased as the $\mathrm{pH}$ increased from 3 to 11 . Under acidic $\mathrm{pH}, \mathrm{O}_{3}$ molecule is main reactive species and its reactivity is very low relative to hydroxyl radical, so the degradation of tetradifon very low. As the solution becomes more basic, the rate of photocatalyzed decomposition of ozone to secondary oxidants, such as hydroxyl radicals increases. While the increase in $\mathrm{pH}$ facilitates the hydroxyl radical concentration, the effect of $\mathrm{pH}$ 
on the substrate reactivity is also equally vital for efficient conversion. The obtained results indicate that the process effectiveness increases significantly and highest conversion was recorded at $\mathrm{pH} 11$.
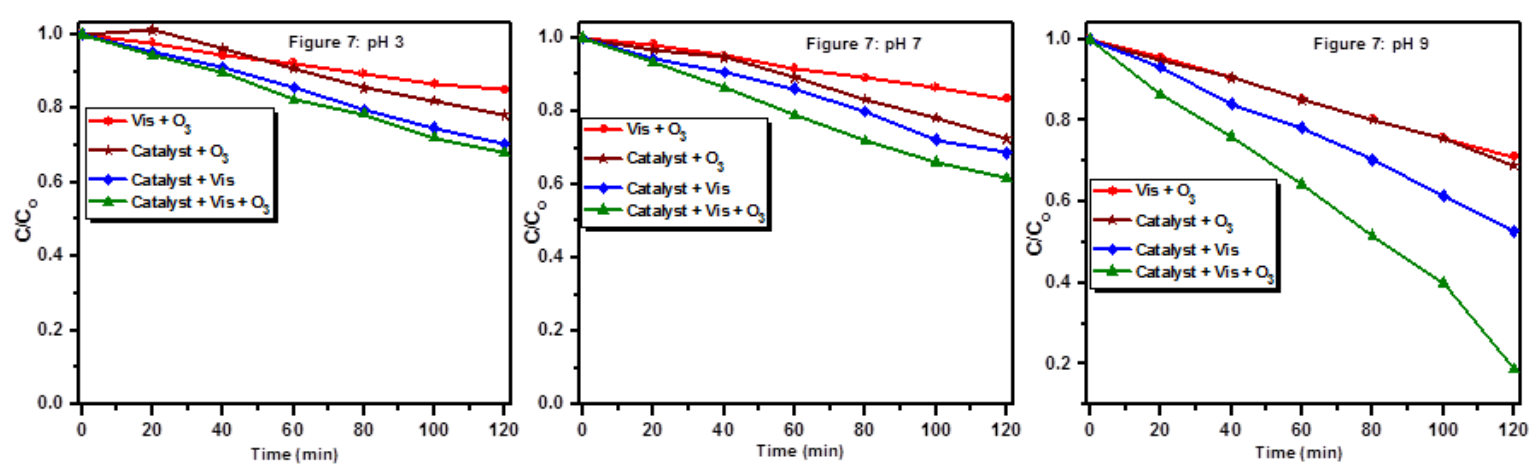

Figure 7. Effect of the different photooxidations at $\mathrm{pH} 3,7$ and 11

\subsection{Effect of catalyst concentration}

The effects of catalyst concentration on the tetradifon photodegradaion, It is observed from Figure. 8. The photocatalytic efficiency of the tetradifon samples increases up to the catalyst concentration of 0.05 to $0.250 \mathrm{~g} \mathrm{~L}^{-1}$, for the tetradifon photooxidation. The optimum weight of catalyst loading was found to be $0.1 \mathrm{~g} \mathrm{~L}^{-1}$. Further increase in catalyst weight resulted in the decrease of the reaction rate. This can be explained in terms of availability of active sites on the catalyst surface and the penetration of visible light into the suspension (Oseghe et al., 2015). The total active surface area increases with increasing catalyst weight but at the catalyst weight above optimum loading decrease in visible light penetration may be due to screening effect of excess catalyst particle in the solution. Hence, the initial rate decreases at the higher catalyst loading.

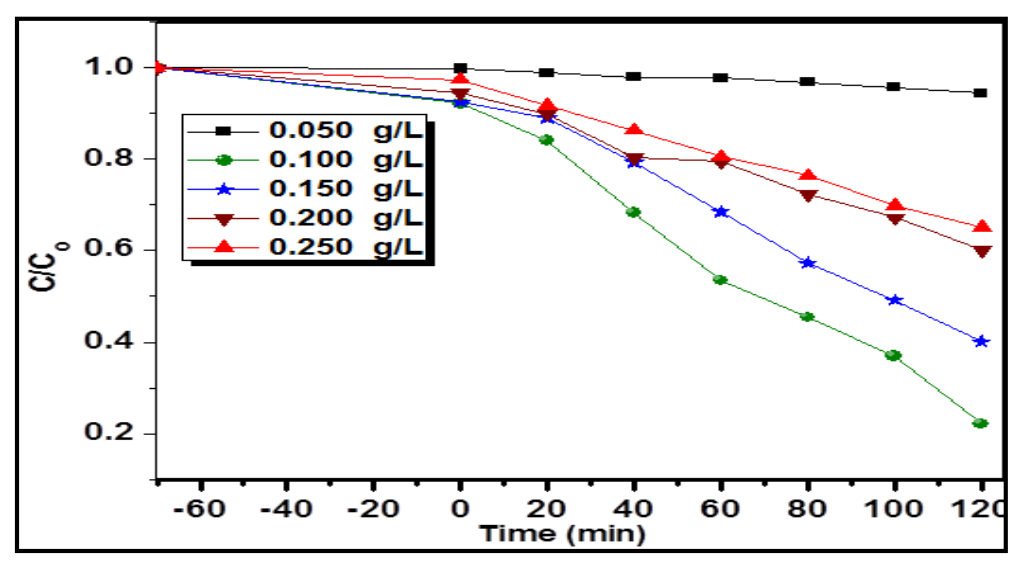

Figure 8. Effect of $\mathrm{Mn} / \mathrm{TiO}_{2}$ catalyst concentration at $\mathrm{pH} 11$

\subsection{Effect of Mn doping concentrations}

Photo induced oxidation of tetradifon in the presence of the bare $\mathrm{TiO}_{2}$ and $\mathrm{Mn}$ on titania was carried out in order to study the photocatalytic activity under visible light. The photocatalytic activity of $\mathrm{Mn} / \mathrm{TiO}_{2}$ photocatalyst was significantly enhanced on the addition of Mn loading. Additionally, the photocatalytic activity of $\mathrm{Mn}$ doped titania increased with the increasing doping concentration of $\mathrm{Mn}$ (1 to $5.0 \%)$. An increase in the amount of $\mathrm{Mn}$ dopant resulted in the increasing visible light absorption and hence 
enhanced photocatalytic activity. The optimal tetradifon degradation was found to be at $5 \mathrm{wt} . \% \mathrm{Mn}$ concentration with the removal efficiency.

\subsection{Catalyst testing and product identification}

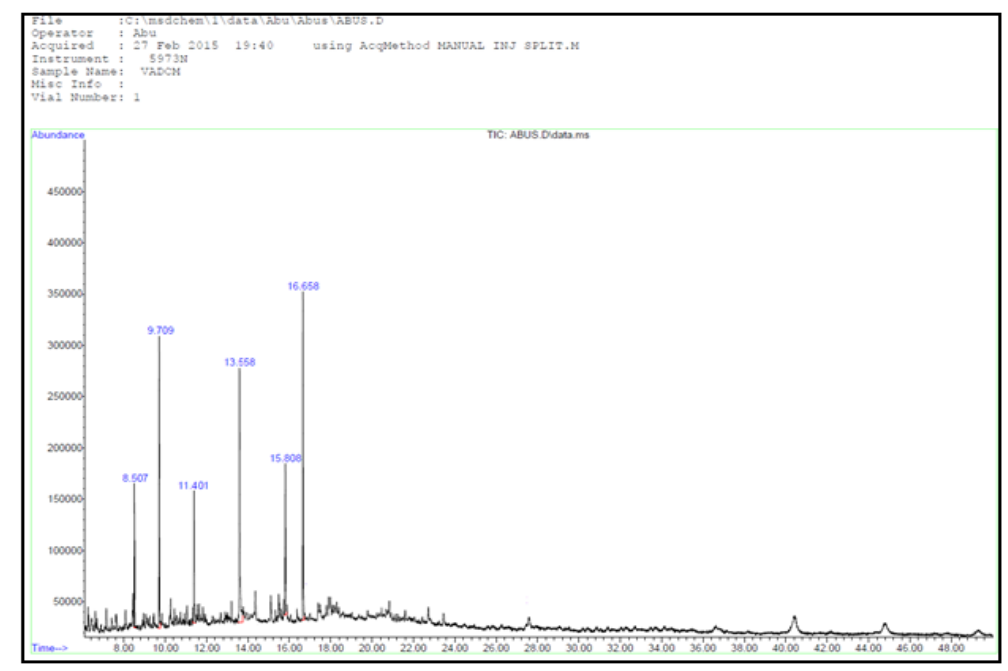

Figure 9. GC-MS chromatogram of product mixture

All the photocatalyzed ozonation experiments were accompanied by exposing the reaction mixtures with visible light and with a flow of ozone enriched oxygen. After ozone aeration, the organic portion of the reaction mixture was extracted and analyzed after every reaction with $20 \mathrm{~min}$ intervals. The six products identified by GC-MS (Figure 9).

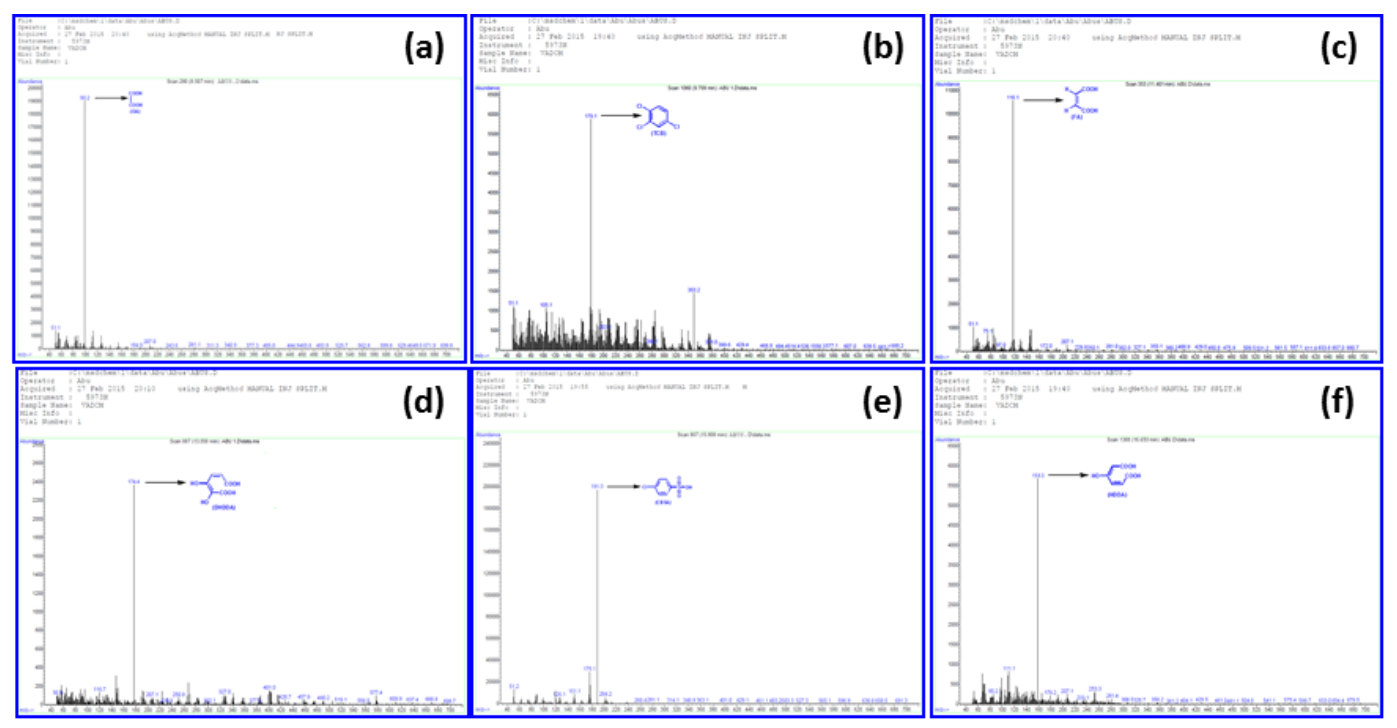

Figure 10. GC-MS mass spectra's products of (a) OA, (b) TCB, (c) FA, (d) DHDDA, (e) CBSA and (f) HDDA

The peaks from 8.00-17.00 retention times refer to the intermediates and various carboxylic acid compounds formed due to the further oxidation of the products of the reaction. The peaks at retention time 8.507, 9.709, 11.401, 13.558, 15.807 and 16.658 minutes refer to the compounds of (a) oxalic acid $(\mathrm{OA})$, (b) trichlorobenzene (TCB), (c) fumaric acid (FA), (d) dihydroxyhexa-2,4-dienedioic acid (DHDDA), (e) 4-chlorobenzenesulfonic acid (CBSA), and (f) 3-hydroxyhexa-2,4-dienedioic acid (HDDA) respectively. 
Furthermore, the formation of these products was confirmed by GC-MS with their respective $\left(M^{+}\right) \mathrm{m} / \mathrm{z}$ values (Figure 10a-f). The peaks observed in ${ }^{1} \mathrm{H}-\mathrm{NMR}$ and FT-IR spectra of the products were in good agreement with spectra of the functional groups present in the products. Additionally, the qualitative lime water test confirmed the release of $\mathrm{CO}_{2}$ during the reactions and suggested some mineralization of pesticides. Photo catalytic ozonation of pesticides in water is known to produce more biodegradable oxygenated organic products and low molecular weight acids.

\subsection{Reaction mechanism}

Based on the observed experimental results, the probable mechanism for the photocatalysed degradation of tetradifon on $\mathrm{Mn} / \mathrm{TiO}_{2}$ in presence of ozone is proposed. In photocatalysed ozonation using heterogeneous catalyst, the photoinduced holes and electrons in semiconductor particles reportedly produce highly oxidizing species, which play a key role in degradation of organic pollutants (Zhang et al., 2009). The heterogeneous photocatalysed ozonation in the presence of metal oxides or metals/metal oxides on supports, the effectiveness of the catalytic process depends to an abundant scope on the properties of catalyst surface, which influence the properties of the surface active sites and photocatalysed ozone decomposition reactions in aqueous solutions. The most important chemical properties for the sustainable activity of catalyst are chemical stability and the presence of active surface sites, which are responsible for catalysed reactions (Kasprzyk-Hordern et al., 2003).

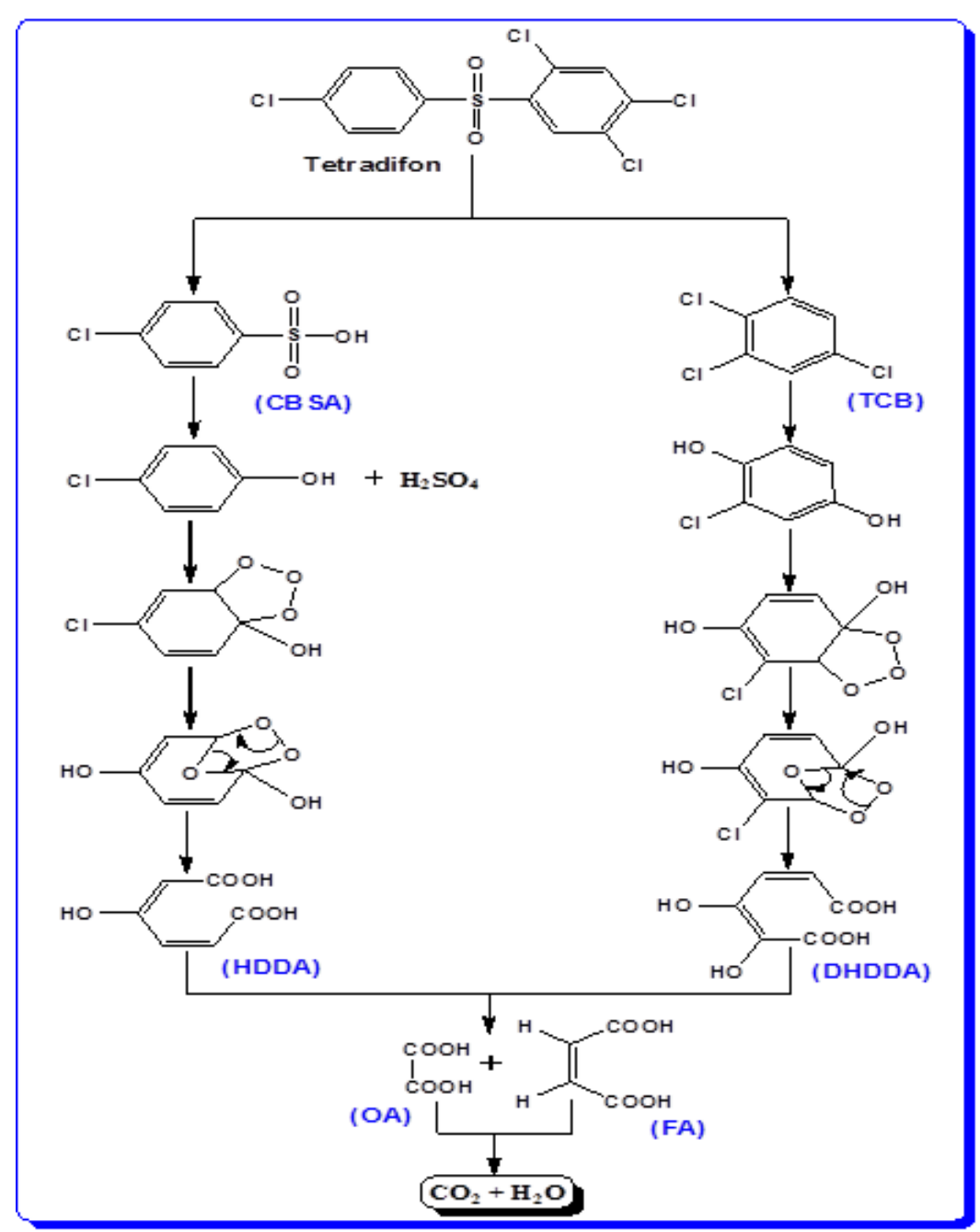

Proposed Mechanism: Mechanism of the Scheme 
It is well well-known that the electrophilic reactions of photolytic ozone take place on sites with strong electronic density. In particular, aromatics substituted with electron-withdrawing groups are highly reactive with photoinduced ozone electrons on carbons located in the ortho and para positions due to high electronic densities on these aromatic carbons whereas aromatics substituted with electron withdrawing groups $\left(-\mathrm{SO}_{2},-\mathrm{Cl}\right)$ are weakly photolytically reactive. The molecular structure of tetradifon pesticide contains electron-withdrawing groups $\left(-\mathrm{SO}_{3}\right.$ and $\left.-\mathrm{Cl}\right)$, hence photolytically ozone reactions should occur initially on certain preferential sites. In order to illustrate this, sites with strong electronic density were identified, and the analysis showed that it is likely that photocatalyzed ozone attack would take place at the sulfonyl group. Besides the electrophilic attack, ozone undergoes cycloaddition reaction with unsaturated bonds leads to the formation of compounds having the carbonyl group $(-\mathrm{C}=\mathrm{O})$ or the acid group $(-\mathrm{COOH})$.With this in mind and in order to illustrate a possible reaction mechanism, further analysis was made with spectral analysis to identify the intermediate products. Based on, the sulfone compound, 4-chlorobenzenesulfonic acid (CBSA) and trichlorobenzene (TCB). According to this postulate that the bonds $\mathrm{C}-\mathrm{S}$ and $\mathrm{C}-\mathrm{Cl}$ in $\mathrm{A}$ and $\mathrm{B}$ are cleaved leading to the formation of another intermediates 4chlorophenol and 2-chlorobenzene-1,4-diol. Further attacks of photoozone radicals leads to the conversion of 4-chlorophenol to 3-hydroxyhexa-2,4-dienedioic acid (HDDA), then to oxalic acid (OA) and also fumaric acid (FA), and eventually conversion to mineralization $\left(\mathrm{CO}_{2}\right.$ and $\left.\mathrm{H}_{2} \mathrm{O}\right)$.

On the other hand, through cleavage of the $\mathrm{C}-\mathrm{Cl}$ bond in compound trichlorobenzene (TCB) and with further photolytic ozone attack, dihydroxyhexa-2,4-dienedioic acid (DHDDA) is formed. Through further photolytic ozone attack, OA and FA are converted. Additionally, extended photolytic oxidation of the intermediates leads to complete mineralization to produce carbon dioxide and water (Scheme).

\section{Conclusions}

Our study showed that the deposition-precipitation method permits the synthesis of Mn doped titania catalysts with good metal dispersion. The results of this study clearly indicate that $\mathrm{Mn} / \mathrm{TiO}_{2}$ can effciently catalyze the degradation and mineralization of the tetradifon pesticide in the presence of light and ozone. The size of catalyst particles, and reaction parameters play a significant role in ozonolysis, so catalytic properties are strongly affected by the preparation method of the catalyst. Titania is a suitable support for loading of $\mathrm{Mn}$ catalysts. The tetradifon photooxidation was quantitative with $100 \%$ degradation. CBSA, TCB, HDDA and DHDDA were main products of which OA and FA were the secondary product, with partial mineralization. Photocatalysed ozonation is proved to be an effective method to remove chloro, sulfonyl and hydroxy groups from substituted organic pesticide.

\section{Acknowledgements}

The authors are thankful to the National Research Foundation of South Africa, University of KwaZulu-Natal, Durban, South Africa and Department of Chemistry, Annamacharya Institute of Technology \& Sciences, Tirupati, India for providing facilities.

References

Angelidaki I., Mogensen A.S., and Ahring B.K. (2000), Degradation of organic contaminants found in organic waste. Biodegradation 11, 377-383.

Aragay G., Pino F. and Merkoci A. (2012), Nanomaterials for sensing and destroying pesticides, Chem. Rev., 112(10), 5317-5338.

Chen C., Ma W and Zha J. (2010), Semiconductor-mediated photodegradation of pollutants under visible-light irradiation. Chem. Soc. Rev., 39, 4206-4219.

Chong M.N., Jin B., Chow C.W.K. and Saint C. (2010), Recent developments in photocatalytic water treatment technology: A review. Water Res., 44(10), 2997-3027.

Dahl M., Liu Y. and Yin Y. (2014), Composite titanium dioxide nanomaterials. Chem. Rev., 114(19), 9853-9889.

Fathinia M., Khataee A., Naseri A. and Aber S. (2015). Monitoring simultaneous photocatalytic-ozonation of mixture of pharmaceuticals in the presence of immobilized $\mathrm{TiO}_{2}$ nanoparticles using MCR-ALS: Identification of 
intermediates and multi-response optimization approach, Spectrochimica Acta Part A: Mol \& Biomol. Spectro., 136(C), 1275-1290.

Field J.A and Sierra-Alvarez R. (2008) Microbial transformation and degradation of polychlorinated biphenyls, Environ. Poll., 155(1), 1-12.

Huber M.M., Canonica S., Park G-Y and Von Gunten U. (2003), Oxidation of pharmaceuticals during ozonation and advanced oxidation processes, Environmental Science and Technology, 37(5), 1016-1024.

Kabra K., Chaudhary R. and Sawhney R.L. (2004), Treatment of hazardous organic and inorganic compounds through aqueous-phase photocatalysis: A Review, Ind. Eng. Chem. Res., 43(24), 7683-7696.

Kasprzyk-Hordern B., Ziolek M. and Nawrocki J. (2003). Catalytic ozonation and methods of enhancing molecular ozone reactions in water treatment, Appl. Catal. B: Environ., 46, 639-669.

Maddila S., Dasireddy V.D.B.C and Jonnalagadda S.B. (2013a), Dechlorination of tetrachloro-o-benzoquinone by ozonation catalyzed by cesium loaded metal oxides, Appl. Catal. B: Environ., 138-139, 149-160.

Maddila S., Dasireddy V.D.B.C. and Jonnalagadda S.B. (2014a), Ce-V loaded metal oxides as catalysts for dechlorination of chloronitrophenol by ozone, Appl. Catal. B: Environ., 150-151, 305-314.

Maddila S., Dasireddy V.D.B.C. and Jonnalagadda S.B. (2014c), Ce-V loaded metal oxides as catalysts for dechlorination of chloronitrophenol by ozone, Appl. Catal. B: Environ., 150-151, 305-314.

Maddila S., Dasireddy V.D.B.C., Oseghe E.O. and Jonnalagadda S.B. (2013b), Ozone initiated dechlorination and degradation of trichlorophenol using Ce-Zr loaded metal oxides as catalysts, Appl. Catal. B: Environ., 142-143, 129-141.

Maddila S., Oseghe E.O. and Jonnalagadda S.B. (2016), Photocatalysed ozonation by Ce doped $\mathrm{TiO}_{2}$ catalyst degradation of pesticide, Dicamba in water, J. Chem. Technol \& Biotechnol., 91, 385-393.

Maddila S., Palakondu, L. and Jonnalagadda S.B. (2015a), Degradation, mineralization of bromoxynil pesticide by heterogeneous photocatalytic ozonation, J. Indu. \& Eng. Chem., 24, 334-341.

Maddila S., Rana S., Pagadala R., Maddila S.N., Chandrasekhar, V. and Jonnalagadda S.B. (2015b), Ozone driven photocatalyzed degradation and mineralization of pesticide, Triclopyr by Au/TiO 2 , J. Environ. Sci. \& Heal. B, 50, 1-13.

Oseghe E.O., Ndungu P.G., and Jonnalagadda S.B. (2015), Synthesis of mesoporous $\mathrm{Mn} / \mathrm{TiO}_{2}$ nanocomposites and investigating the photocatalytic properties in aqueous systems, Environ. Sci. Pollut. Res., 22, 211-222.

Rissato S.R., Galhiane M.S., de Almeida M.V., Gerenutti M. and Apon B.M. (2007), Multiresidue determination of pesticides in honey samples by gas chromatography-mass spectrometry and application in environmental contamination, Food Chem., 101(4), 1719-1726.

Venieri D., Fraggedaki A., Kostadima M., Chatzisymeon E., Binas V., Zachopoulos A., Kiriakidis G and Mantzavinos D. (2014), Solar light and metal-doped $\mathrm{TiO}_{2}$ to eliminate water-transmitted bacterial pathogens: Photocatalyst characterization and disinfection performance, Appl. Catal. B: Environ., 154-155, 93-101.

Zhang W., Zou L. and Wang L. (2009). Photocatalytic $\mathrm{TiO}_{2} /$ adsorbent nanocomposites prepared via wet chemical impregnation for wastewater treatment, Appl. Catal. A: Gene., 371(1-2), 1-9. 